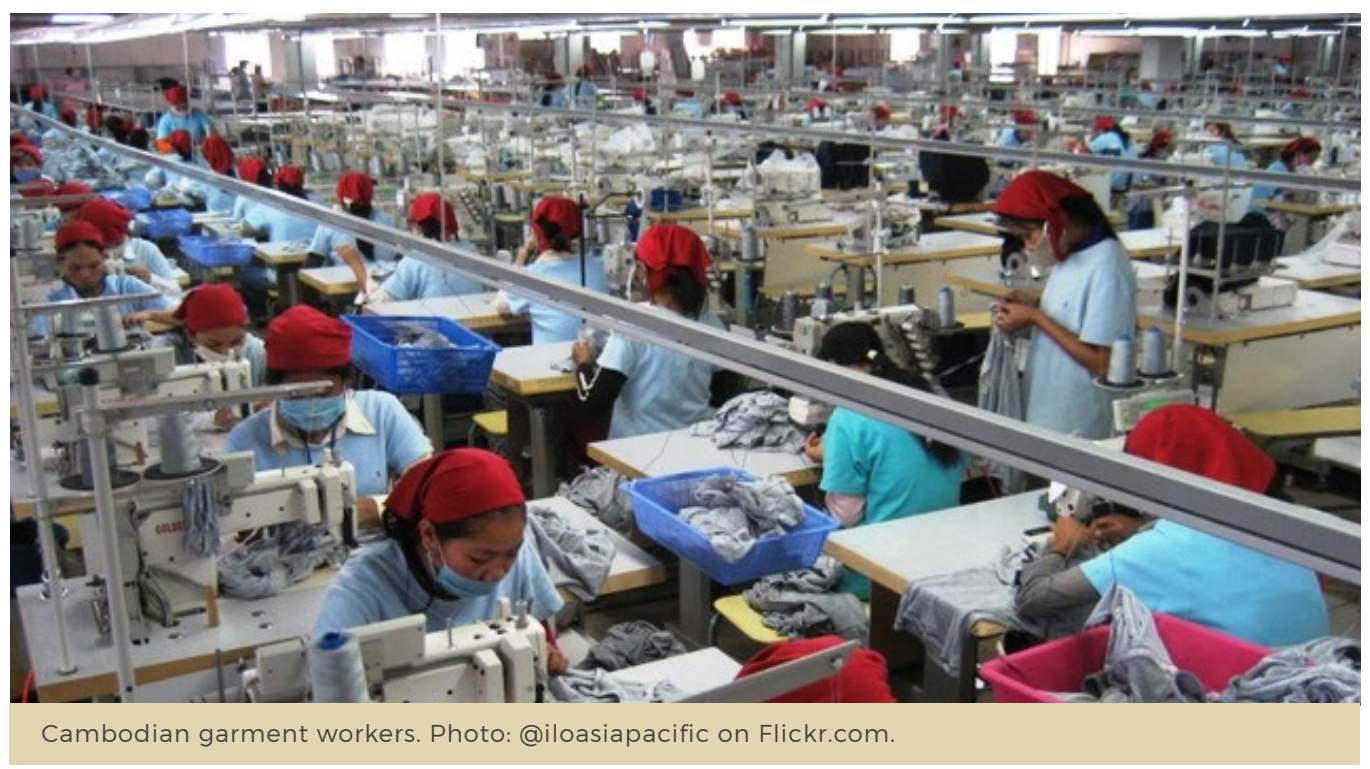

\section{Outsourcing Exploitation Chinese and Cambodian Garment Workers Compared}

\section{Ivan Franceschini}

In recent years, much has been written about how increasing labour costs in China are pushing investors to move labour-intensive production to other countries where wages are still low. But what does this shift in global capital trends entail for workers? How do the workforces in these new outsourcing destinations fare compared to their Chinese counterparts? In order to gain a better understanding of the human cost of this latest capital flight, this essay compares garment workers in China and Cambodia, considering the wages they receive in relation to the context of their expectations and needs.
In recent years, much has been written about how increasing labour costs in China-among other factors-are pushing investors to move labour-intensive production to other countries where wages are still low. Due to its moderate capital requirements, low level of automation, and minimal demands in terms of skills, the garment industry is one of the sectors in which China's loss of competitiveness is felt most acutely-especially as other countries, such as Bangladesh, Vietnam, Myanmar, and Cambodia, adopt policy after policy to entice foreign investors. But what does this shift in global capital trends entail for workers? How do the workforces in these new outsourcing destinations fare compared to their Chinese counterparts? There is no easy answer to these questions. Indeed, while the past two decades have seen a broad theoretical debate about the consequences and extent of the global 'race to the bottom' in labour standards, not much attention has yet been paid to the human costs of the wave of capital flight that is taking place in the wake of China's industrial upgrade. To address this gap, in this essay I will compare 
garment workers in China and Cambodia, considering the wages they receive in the context of their expectations and needs.

The choice of these two countries is dictated by the fact that the garment industry in China and Cambodia is at two different stages of development. While China remains the undisputed global leader in the industry, with its 2015 exports worth approximately 274 billion USD, there are already signs that the Chinese garment sector is unravelling due to rising labour costs, as the country embarks on an ambitious path of industrial upgrading (Van Der Kamp 2016). The Cambodian garment industry, on the other hand, was only established in the mid-1990s, when Cambodia finally emerged from more than two decades of chaos, and maintains a positive outlook. Having started from barely 80 million USD of exports in 1996, in 2015, the Cambodian garment sector had become a 6.8 billion USD industry, the ninth largest in the world (ILO 2017). Of course, the weight of the two industries within their respective local economies is very different. While the garment industry today plays a relatively minor role in China-in 2015 only 12 percent of the Chinese merchandise exports were in the garment sector-Cambodia's economic growth remains heavily dependent on garment production, with about 610,000 workers employed in the sector in 2016 and as much as 80 percent of the country's total merchandise exports in the same year being garment and footwear products.

To explore these different contexts, during the summer of 2016 I undertook two surveys. The first was conducted in June and July 2016 at three Hong Kong-owned garment factories in Dongguan, Guangdong province. These factories employed 2,000, 1,000 , and 800 workers respectively, and I was able to collect a total of 250 completed questionnaires. The second survey was carried out from July to September 2016 in three Hong Kong-owned garment factories in Phnom Penh, where most of the Cambodian garment industry is concentrated. In this case, the factories employed 5,700, 2,100, and 1,100 workers, and I collected a total of 291 questionnaires. To avoid interference from the management and possible biases in the responses of the workers, all respondents were approached outside the factory without prior knowledge of their employer. Most often, the meetings took place in the safety of their accommodation after their shift had ended or in restaurants around the factory during their lunch break. The quantitative data were supplemented with forty semi-structured interviews with garment workers employed in the sampled

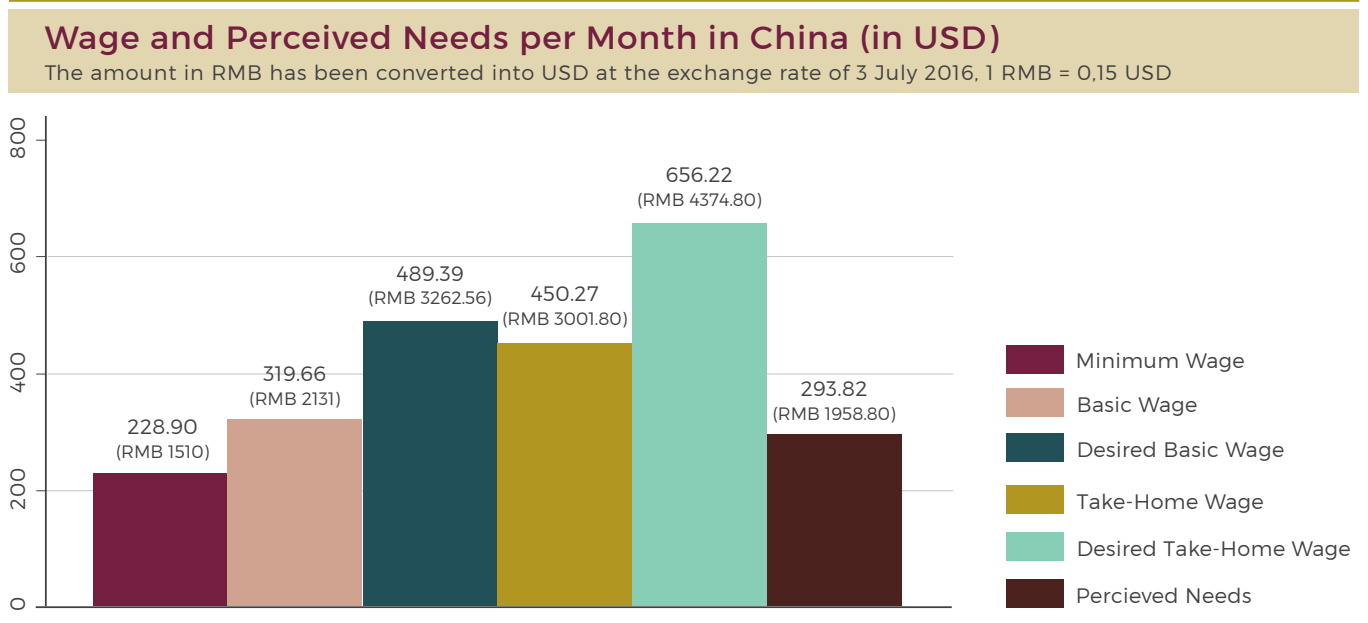




\section{Wage and Perceived Needs per Month in Cambodia (in USD)}

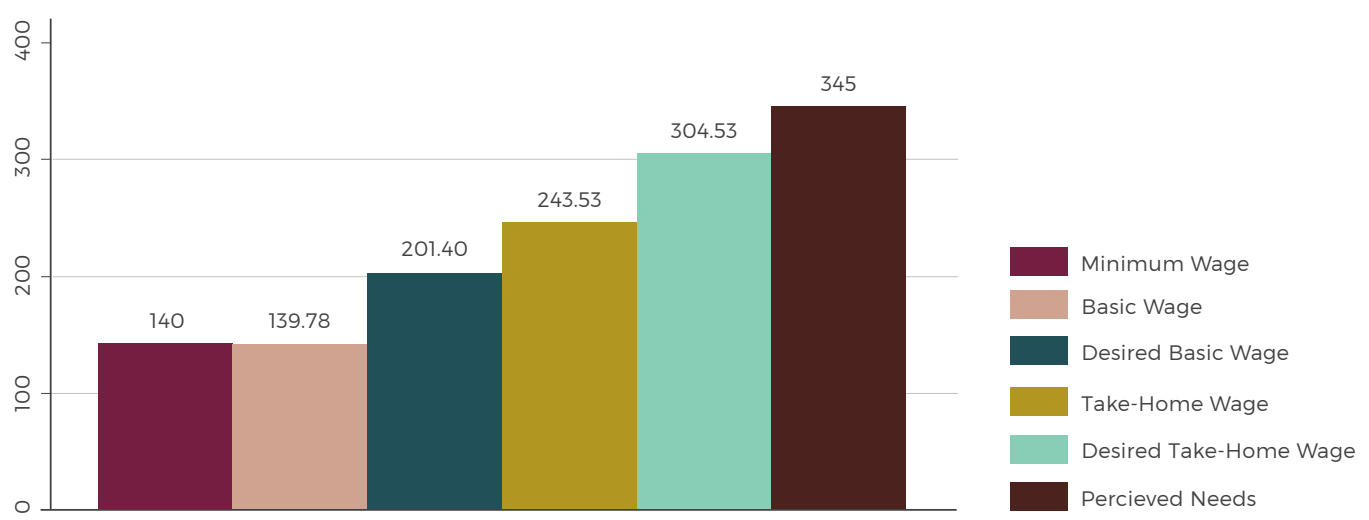

factories in both countries, plus additional interviews with local lawyers specialising in labour disputes, union leaders, and labour activists.

\section{Basic Guarantees}

The two graphs that accompany this essay summarise my findings. The first aspect to consider when comparing the two countries is the level of wages guaranteed by law, i.e. the local minimum wage. This is depicted in the first column in both graphs. According to the Chinese labour legislation, local governments in China are allowed to decide their own minimum wage through a process of tripartite consultation between local labour departments, the official trade union, and business associations. In setting the amount, these actors have to consider several factors, including the cost of living, the percentage of social security contributions paid by the workers, the average salary in the area, the unemployment rate, and the local level of development. At the time of the survey, the minimum wage in Dongguan was set at 1,510 RMB (roughly 229 USD) per month. In Cambodia, in 2016, authorities announced their intention to pass a Minimum Wage Law that would lay the foundations for a 'universal minimum wage' to be determined every year through 'tripartite consultation' (Bun and Davis 2016). However, currently only the garment and footwear sector is covered by a minimum wage, which is the same for the whole country. The amount is decided every year by the central government on the basis of the recommendation coming from a tripartite Labour Advisory Committee composed of 28 representatives. Of these, 14 come from the government, 7 from the employers associations, and 7 from the unions (5 of which are considered progovernment). At the time of the survey, the Cambodian minimum wage was set at 140 USD per month.

While in China there are no reported strikes related to minimum wage, in Cambodia the issue is at the centre of much controversy. In early January 2014, massive strikes and demonstrations of garment workers protesting over the government's refusal to raise the minimum wage ended in a bloodbath after the intervention of the military police (AMRC 2014). Due to the increasing repression of civil society and independent unions by the Cambodian authorities (see also NorénNilsson's chapter in the present volume), the following years have seen no more 
mass demonstrations during the minimum wage negotiations. Nevertheless, the raises that were granted by the government have continually fallen short of the expectations of independent trade unions and workerswith the exception of 2017, when the ruling party, concerned about its performance at the impending national elections, actually granted a minimum wage rise in line with the demands of the unions, which went into effect in January 2018 (Sineat and Baliga 2017). In 2016, for instance, independent unions pushed for a new monthly minimum wage of no less than 171 USD, but the government settled on a figure of 153 USD, far closer to the 147 USD proposed by the garment employer association (Baliga and Samean 2016). This was far lower than the 177 USD that some local and global trade unions and advocacy groups had been demanding as a 'living wage' for Cambodian garment workers since 2014 (Clean Clothes Campaign 2015). In light of these controversies, it is unsurprising that the draft Minimum Wage Law mentioned above introduces severe restrictions on the ability of independent unions to negotiate for higher minimum wages. One example of this is the inclusion of clauses that allow for fines of up to 1,250 USD for those 'creating obstacles or putting illegal pressure on discussions to determine the minimum wage', or up to 2,500 USD for anyone who 'incites activities against the declaration of the minimum wage' (Bun and Davis 2016).

Why do negotiations about the minimum wage elicit such different responses from Chinese and Cambodian workers? The reason can be found in the second column of both graphs, which depicts the basic wage, i.e. the monthly amount that the factories guarantee to the workers regardless of their actual workload. While the Cambodian factories offered a basic wage that coincided with the minimum wage, in China the basic wage was significantly higher (41.1 percent more) than the legal minimum.
The explanation for this disparity can be found in the cyclical 'labour famines' (mingonghuang) that have hit coastal areas in China, including Guangdong province, since the early 2000s (Zhang and Liu 2012). With many young Chinese rural women deciding to stay home to raise a family or to look for a job in townships closer to their hometowns, companies in labour-intensive sectors such as the garment industry have no other choice than to offer salaries higher than the legal minimum in order to attract workers. This means that while increases in the minimum wage in Cambodia have a direct impact on the income of the workers, in China workers already receive higher basic salaries and therefore do not have a large stake in the government's decisions on the matter. Most importantly, it shows that due to reasons related to demography, as much as to local development, Chinese workers have much more bargaining power than their Cambodian counterparts-a much more threatening prospect for investors than a difference of a few dozen dollars in the minimum wages.

\section{Expectations and Perceived Needs}

Minimum wages are simply a bottom line that is somehow supposed to protect workers from extreme exploitation, providing them with the guarantee of an income at times when production slows down due to the paucity of orders. As such, they do not reflect the actual level of remuneration that the workers receive, which in both China and Cambodia largely depends on the amount of overtime work. The Chinese workers in my sample worked an average of 10.3 hours a day from Monday to Friday, plus an average of 9.9 hours on Saturdays, with only Sundays off. This is a clear violation of the national labour law, which states that workers should work no more than 8 hours a 
day and 44 hours a week, with a maximum of 36 hours of overtime a month. In Cambodia, the workers worked 9.7 hours a day from Monday to Saturday and got only one day off every two weeks, another clear violation of the national legislation, which allows for 48 hours a week, with no more than 2 hours of overtime a day.

Due to the large amount of overtime, workers in both countries were able to earn more than the local minimum wage. This can be seen clearly from the fourth column of both graphs, which depicts the take-home wage, i.e. how much the workers were actually paid after taxes and other deductions for social security. In absolute terms, Chinese garment workers received much higher take-home wages compared to their Cambodian counterparts. While the Chinese workers in my sample were given an average take-home wage of 3,001.76 RMB (roughly 450.30 USD) a month, Cambodian workers were paid only 243.53 USD, a gap which would most likely widen if the survey also included the costs born by the companies for social insurance and other welfare-related expenses, burdensome in China and almost non-existent in Cambodia. In this sense, the assumption that rising labour costs underscores industrial relocations from China to other countries indeed has a strong foundation.

Significantly, both workforces were not satisfied with their remuneration levels. The third column of both graphs shows the desired basic wage, i.e. the response to the question in a situation in which you have to work only 40 hours a week [ 48 hours in Cambodia] and do not have to work overtime, how much do you think a reasonable salary would be?' Comparing the desired basic wage with the actual basic wage highlights that workers in both countries thought it reasonable to receive much higher wages for working only ordinary hours, with the Chinese workers wanting 53.1 percent more and the Cambodian workers wanting 44.1 percent more. The same frustration emerged when the workers were asked about their desired take-home wage. The question, depicted in the fifth column of both graphs, was formulated as such: 'Considering your current workload, how much do you think would be a reasonable salary for you?' While Chinese workers considered 4,374.80 RMB (roughly 656.20 USD) to be a reasonable amount, 34.1 percent more than their takehome wage, Cambodian workers desired 304.53 USD, that is 'only' 25 percent more than what they were currently making.

Still, the roots of this dissatisfaction cannot be understood without considering the perceived economic needs of the two workforces, which are displayed in the sixth column of the graphs. As mentioned above, international advocacy groups and Cambodian independent unions have been campaigning since 2014 for a living wage of 177 USD per month. An unpublished survey undertaken by several unions and NGOs in Cambodia in June 2016 found that workers in Phnom Penh needed around 142 USD a month for their living expenditures. Yet, as Dennis Arnold has noted, 'workers' politics and livelihood concerns [in Cambodia] include and extend beyond the (peri-) urban factory floor to rural households' $(2017,26)$. For this reason, in my survey I decided to go beyond basic living expenses and ask: 'On average, how much do you think you need every month to cover the basic living expenses of yourself and your immediate family (your partner, children, parents, or other people whom you have to support)?'

The responses were surprising, considering that living costs are much higher in Dongguan than in Phnom Penh. Cambodian workers felt they needed an average of 345 USD per month, more than the 1,958.80 RMB (roughly 293.80 USD) required by the Chinese workers. One initial explanation for this counterintuitive finding is that most Cambodian workers came from extended families-besides their parents, 
84.2 percent of them had three siblings or more-with most family members remaining in the countryside to engage in agricultural work. A second reason is that while 82.4 percent of the Chinese workers in my sample lived in a dormitory provided by the factory-evidence of the persistence of the so-called 'dormitory labour regime' in today's China (Smith and Pun 2006)-and thus paid only a symbolic fee for water, gas, and electricity averaging 122 RMB (roughly 18.30 USD) a month, Cambodian workers had to find private accommodation outside the factory, paying an average of 34.40 USD monthly. Chinese workers also had access to much cheaper food, paying $311.57 \mathrm{RMB}$ (approximately 46.70 USD) for their meals on average, compared to the 71.66 USD paid by Cambodian workers. This disparity in expenses clearly affected the amount of funds sent home. While Chinese workers were able to remit 1,724.90 RMB (roughly 258.70 USD) a month, i.e. 57.5 percent of their take-home wage, Cambodian workers could only send 67.55 USD, i.e. 22.2 percent of their take-home wage.

\section{A Matter of Survival}

What does this comparison tell us about the implications of the decline of the garment industry in China? First, it says that labour costs-as shown by the data on minimum wages and take-home wages - are indeed much higher in China than in Cambodia. This situation is further compounded if we consider the likely impact of the various costs related to social security and welfare that the companies must bear-costs which are substantial in China and almost nonexistent in Cambodia. Even more important, in order to face the challenges posed by demographic trends and local development, garment factories in China today often have no other choice than to offer better conditions than the legal minimum wage in order to attract workers. This is in stark contrast to Cambodia, where most employers have no incentive whatsoever to provide anything more than to what they are legally bound. In such a context, although China still offers advantages in terms of infrastructure and the availability of raw materials, investments in labour-intensive industry are likely to continue to desert the country.

Second, my survey demonstrates that by relocating from China to Cambodia, investors perpetuate dynamics of exploitation. This emerges clearly from the data regarding the expectations and perceived needs of the workers in the two countries. While the Chinese workers in my sample were finally able to earn wages higher than what they felt they needed, their Cambodian counterparts still earned much less than their perceived needs. It was definitely not a coincidence that wages were never at the top of the list of the workers' concerns during my interviews in China, while they regularly came up in my conversations in Cambodia. This does not mean that Chinese garment workers are happy with their remuneration-on the contrary, as we have seen, they still deem wages 'unreasonable' in light of their workload. Still, there is a fundamental difference between dissatisfaction due to the perceived unfairness of the economic treatment experienced in the workplace, as I found in China, and a deeper concern about the ability to provide a basic level of subsistence for oneself and one's family, as I encountered in Cambodia. It is this kind of human cost that employers should bear in mind when deciding to relocate from one country to the next in their unending quest for lower costs and higher profits. 
This text is taken from Gilded Age: A Year of Chinese Labour, Civil Society, and Rights, Made in China Yearbook 2017, edited by Ivan Franceschini and Nicholas Loubere, published 2018 by ANU Press, The Australian National University, Canberra, Australia.

doi.org/10.22459/MIC.04.2018.13 